\title{
A STUDY OF DIAGNOSTIC ACCURACY AND UTILITY OF ULTRASOUND IN THE ASSESSMENT OF BILIARY STENT
}

Prashant U. Titare1, Bhawana D. Sonawane², Narendra G. Tembhekar3, Pradip B. Rathod4, Amitkumar W. Kamble5, Aarti Anand6, Suhasini N. Patil7, Abhishek Mashirkar

\section{HOW TO CITE THIS ARTICLE:}

Prashant U. Titare, Bhawana D. Sonawane, Narendra G. Tembhekar, Pradip B. Rathod, Amitkumar W. Kamble, Aarti Anand, Suhasini N. Patil, Abhishek Mashirkar. "A Study of Diagnostic Accuracy and Utility of Ultrasound in the Assessment of Biliary Stent". Journal of Evolution of Medical and Dental Sciences 2015; Vol. 4, Issue 78, September 28; Page: 13624-13630, DOI: 10.14260/jemds/2015/1948

ABSTRACT: Ultrasound is cheap, easily available imaging modality which is useful in detection of stent within the biliary tree, dilatation of biliary tree and in assessment of complications after ERCP. AIMS AND OBJECTIVE: Our study aims at to statistically assess the diagnostic accuracy and utility of ultrasound in assessment of biliary stent. MATERIAL AND METHODS: Total 221 patients from gastroenterology department were evaluated by ultrasound abdomen examination using Philips HD 11XE ultrasound scanner. Post ERCP clinical details were obtained. X-ray abdomen done in all cases with ERCP is done wherever required. RESULT: In our study we found following measures of diagnostic accuracy in detection of biliary stent. Sensitivity $77.27 \%$, Specificity $94.59 \%$, Accuracy 85.97\%, Positive predictive value 93.40\%, Negative predictive value $80.76 \%$, Positive likelihood ratio 14.29, Negative likelihood ratio 0.24 , Diagnostic odds ratio 59.50. Twenty cases showed biliary dilatation in presence of CBD stent. Out of these 4 cases showed presence of upper end of stent in tumor mass while in rest cases it was in dilated biliary tree. Post ERCP complications were noted in 11 cases. CONCLUSION: Ultrasound is a reliable, noninvasive, nonradiative imaging modality to assess presence of biliary stent, biliary dilatation in presence of stent and to assess tumor status and post ERCP complications. Hence we recommend the use of follow up ultrasound after ERCP procedure.

KEYWORDS: Ultrasound, Biliary Stent, Accuracy, Utility.

INTRODUCTION: The first endoscopic biliary stent insertion was done in 1979.1 Ballinger et al 1994 had reported an improvement in quality of life in the patients of obstructive jaundice by biliary stenting at ERCP to relieve jaundice and pruritus. ${ }^{2}$ Previously surgical biliary bypass operation such as cholecystojejunostomy or choledochojejunostomy was the treatment for relief of obstructive jaundice in unresectable malignancy. In obstructive jaundice pruritus and jaundice are due to blockage to the flow of bile into duodenum. Despite continuous advances in surgical care, some cases of malignant biliary obstruction are not curable and require palliative treatment. Biliary stenting is the choice of treatment in such cases to improve quality of life. ${ }^{3}$

Ultrasound is a safe, cheap, noninvasive, easily reproducible imaging investigation which can play important role in the follow up of stents in term of presence or absence of stent in biliary tree, location of upper end of biliary stent, complications of ERCP and biliary stents. Our aim is to estimate the diagnostic accuracy of ultrasound assessment of biliary stent and to observe the utility of ultrasound in patients with biliary stent.

MATERIAL \& METHODS: Total 221 patients with clinical diagnosis of obstructive jaundice having age more than 18 years were included in the study. Study population was collected from the gastroenterology department during period of 3 years (2011 to 2014). 


\section{ORIGINAL ARTICLE}

Ultrasound examination was done on Phillips HD11XE ultrasound scanner by using C5-2 curved array transducer. Examination was done in the morning hours when patients were nil by mouth for 4 hours. Ultrasound was done in radiology department of our hospital. Scanning was done in supine, lateral and oblique positions to visualize the whole biliary tract by a radiologist with adequate experience in hepatobiliary ultrasound imaging. Radiologist was blind about the stent status of the patient.

On ultrasound stent was defined as a presence of two parallel hyperechoic lines within the biliary tract. Additional information such as location of upper end of biliary stent, dilatation of biliary tract in the presence of biliary stent, CBD wall thickening, complete presence of stent in the bowel, bulky hypoechoic pancreas, thick GB wall with positive Murphy's sign were also assessed.

Retrospective data was collected from the gastroenterology department about ERCP done or not, stent placed or not during present hospitalization, history of spincterotomy in present hospitalization, history of previous stenting and timing of previous stenting, history of passage of stent in the stool. USG was done during period of 2 days to 7 days after ERCP. X-ray abdomen done in all cases after ultrasound to detect the presence and location of stent. Follow up ERCP done within 2 days in cases of false negative and false positive cases to confirm the result.

Ultrasound, X-ray abdomen and ERCP data was then analyzed by SPSS. Sensitivity, specificity, negative predictive value, positive predictive value, accuracy, positive likelihood ratio, negative likelihood ratio, diagnostic odds ratio were calculated.

Result:

Out of total 221 patients 121 were male and 100 were female. Age distribution was <20 years- $25,20-40$ year- $85,40-60$ year- 82 , $>60$ years-29. The presenting clinical symptoms include jaundice, abdominal pain, dark stool, pruritus, nausea, vomiting and fever.

Out of these 221 patients data showed that 150 patients underwent ERCP procedure in gastroenterology department of our hospital. Out of these 150 patients, biliary stenting procedure was done in 110 cases. In rest patients stenting was not done.

Out of total 221 cases 91 cases showed stent on ultrasonography (Figure 1A \& 1B). Of these 91 cases ERCP confirm the stent in 85 cases. Six cases which showed stent on ultrasound, ERCP ruled out the presence of stent in these cases.

Figure 1: Ultrasound image (A) showing plastic stent in CBD without dilatation of biliary tree. Ultrasound image (B) showing metallic stent within the CBD.

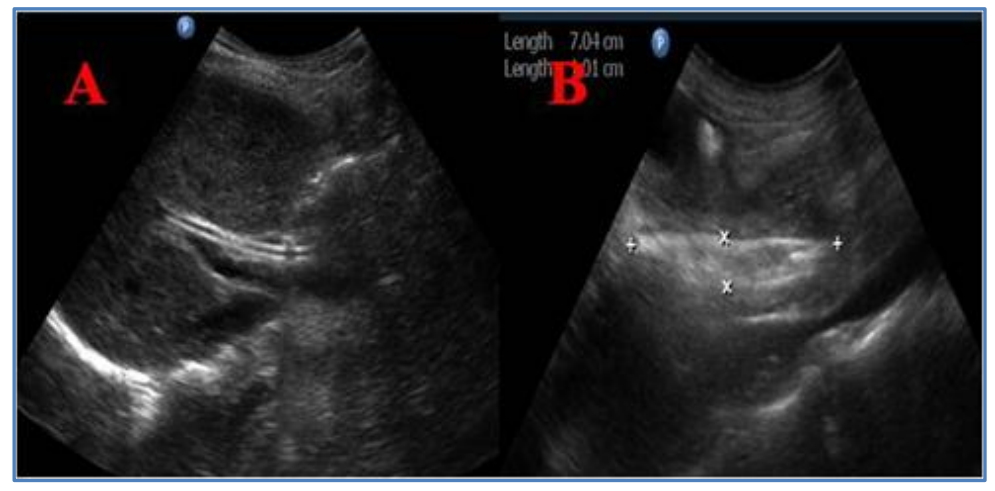

Fig. 1: A \& B 


\section{ORIGINAL ARTICLE}

Biliary tree was not dilated in 65 cases out of 85 cases of biliary stent (Figure-2A). Biliary dilatation was observed in rest 20 cases of biliary stent. Out of these 20 cases, upper end of the stent was present within the dilated biliary tree in 16 cases (Figure-2B) of which one case of metallic stent showed ingrowth of tumor (Figure-2C). In rest four cases upper end of the stent was not present in the dilated biliary tree instead it was present within the mass lesion (Figure-2D).

Figure 2: Ultrasound image (A) showing stent in CBD without dilatation of biliary tree. Ultrasound image (B) showing upper end of stent in dilated CBD. Ultrasound image (C) showing ingrowth of the tumor within stent. Ultrasound image (D) showing upper end of stent within the tumor mass.

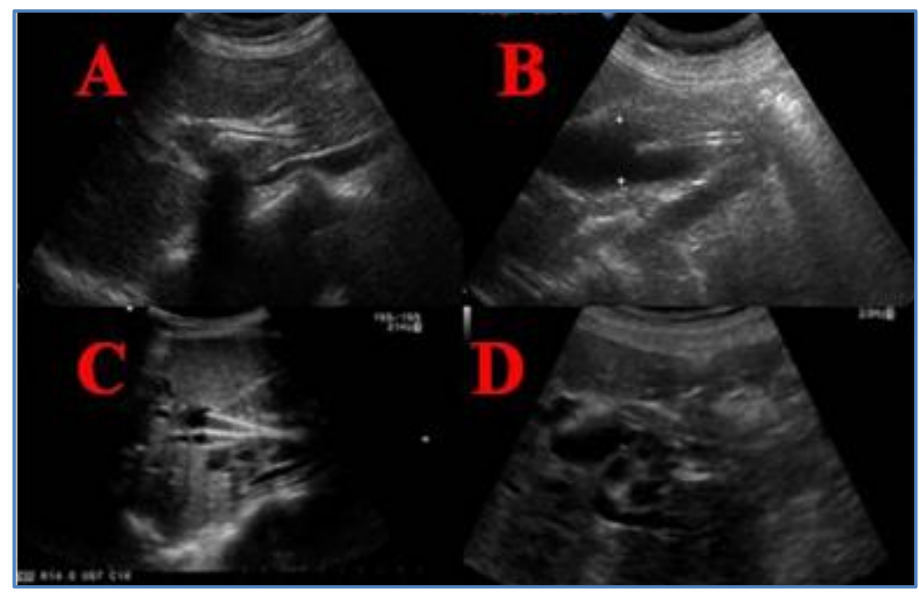

Fig. 2: A ,B, C, D

130 cases did not showed presence of biliary stent on ultrasonography. Out of these 130 cases biliary dilatation was absent in 127 cases. Of these 127 cases, 25 cases showed presence of stent on ERCP. Stent was misdiagnosed as air (Figure- 3A). Stent was absent in biliary tree on ultrasound and ERCP in rest 105 cases. Out of these 105 cases, three cases showed dilated biliary tree. Ultrasound showed presence of stent in one case out of three within the third part of duodenum.

Figure 3: Ultrasound image $(A)$ showing stent in CBD which was misdiagnosed as air. Ultrasound image (B) showing thick gallbladder wall in case of post ERCP cholecystitis.

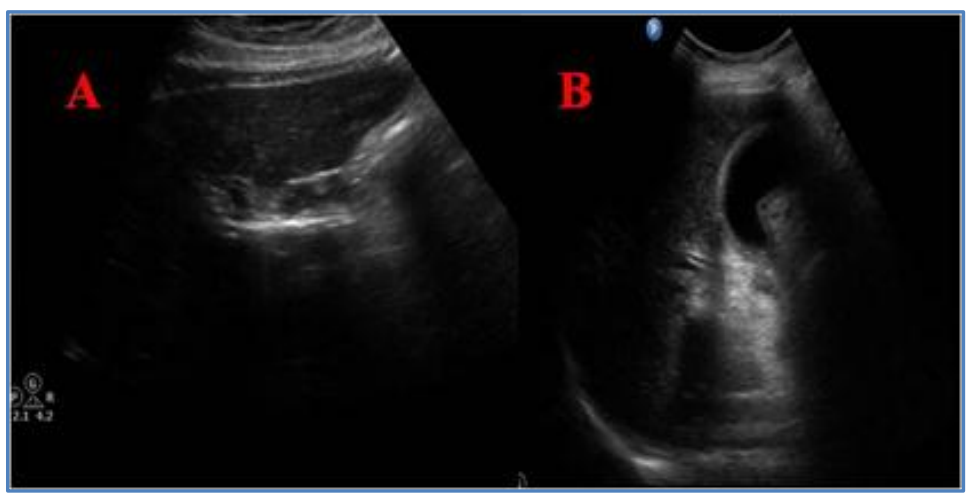

Fig. 3: A \& B 


\section{ORIGINAL ARTICLE}

Analysis showed sensitivity of $77.27 \%$, specificity of $94.59 \%$, PPV of $93.40 \%$, NPV of $80.76 \%$, accuracy of $85.97 \%$, positive likelihood ratio of 14.29 , negative likelihood ratio of 0.24 and diagnostic odds ratio of 59.50 (Table-1). No adverse event was reported in our study. Various complications of ERCP like stent induced cholangitis, cholecystitis (Figure-3B), pancreatitis was found in 5, 4 and 2 cases respectively.

\begin{tabular}{|c|c|c|}
\hline $\begin{array}{l}\text { Sl. } \\
\text { No. }\end{array}$ & $\begin{array}{c}\text { Measures of } \\
\text { Diagnostic Accuracy }\end{array}$ & Result \\
\hline 1. & Sensitivity & $77.27 \%$ \\
\hline 2. & Specificity & $94.59 \%$ \\
\hline 3. & Accuracy & $85.97 \%$ \\
\hline 4. & Positive predictive value & $93.40 \%$ \\
\hline 5. & Negative predictive value & $80.76 \%$ \\
\hline 6. & Positive likelihood ratio & 14.29 \\
\hline 7. & Negative likelihood ratio & 0.24 \\
\hline 8. & Diagnostic odds ratio & 59.50 \\
\hline
\end{tabular}

DISCUSSION: Stents are the hollow tubes which can hold open the structured areas in biliary tract, oesophagus, colon and gastroduodenal region. They are used for definite or palliative treatment of obstructive lesion in benign or malignant cases. Stent insertions primarily involve the placement of guide wire, sometimes with overrunning catheter across the obstruction under endoscopic and fluoroscopic guidence. Through side viewing duodenoscope under endoscopic vision and fluoroscopic guidence biliary stents are positioned. The stent is advanced over the guide wire across the obstruction. Restraining mechanism is released to deploy the self-expanding stents. Stent can be placed endoscopically by gastroenterologist or nonendoscopically by intervention radiologist with the use of combined ultrasound and percutaneous transhepatic cholangiography. ${ }^{3}$

Stents can be of two types such as plastic or self-expandable metallic stent. Initially only plastic stents were used. The plastic stents are composed of one of the polymer such as Teflon, polyethylene or polyurethane. After 1990 self-expandable metallic stents were introduced. Improvement in the stent technology had introduced a new self-expanding metallic stent in 1990. Plastic stent can be straight or pigtail. Straight stents generally have a side flap to prevent migration. Pigtail stent becomes straight over the guide wire during insertion and resume pigtail shape as guide wire has been removed. Pigtail fix the stent into biliary tree. ${ }^{3}$

SEM's are advanced type of biliary stent with multiple benefits. SEM's are positioned using small introducer in collapsed state. These stents are safer without need of stricture dilatation and risk of perforation. SEM's can be made of stainless steel or alloy's and should be biocompatible and MRI compatible. ${ }^{3}$ Tarnita et al 2009 had reported shape memory alloy's with ability to recover defined shape or length when deployed in the patient. ${ }^{[4]}$ SEM's stent when kept across the stricture, the 
constraining mechanism is released and it expands while exerting the radial force on the obstruction area resulting in increase of luminal patency. ${ }^{3}$ Bethge et al 1996 had reported a chronic lymphocytic reaction in the normal tissue underlying the proximal and distal ends of the stent. Stent is embedded in the underlying tissue by chronic lymphocytic reaction with fibrosis and anchor the stent in position. 4

SEM's may be uncovered or covered by silicon membrane. Covering prevent embedment of the stent in underlying tissue and increase the risk of stent migration. Recently biodegradable stents have been reported which breakdown slowly over the time and consist of biodegradable Polydioxanon or Poly L-Lactic acid monofilaments. Stent migration, tumor ingrowth or outgrowth and perforation are the reported complications of SEM stent. ${ }^{3}$

In operable pancreatic head carcinoma if there is delay in surgical resection, biliary stenting should be done. In such a case biliary stenting may be beneficial to reduce jaundice but can lead to cholangitis. In unresectable pancreatic head carcinoma stent placement at ERCP is less invasive treatment compare to surgical biliary bypass procedure. ${ }^{3}$ Studies of Shepherd et al 1988, Anderson et al 1989, Smith et al 1994, Moss et al 2007 had reported relatively fewer complication, shorter hospitalization period and use of resources compare to surgery.6,7,8,9 Higher risk of recurrent biliary obstruction reported with plastic stent compare to surgery.

Ultrasound has a sensitivity of $99 \%$ for detecting biliary dilatation. Sensitivity of $83 \%$ has been reported for acute biliary disease. Ultrasound is the first line imaging investigation of suspected biliary obstruction. ${ }^{10}$ It is noninvasive, fast, easily and widely assessable modality. Ultrasound is used as primary initial imaging modality for the evaluation of bile ducts, gallbladder. ${ }^{11}$ Recent advance ultrasound technique like tissue harmonic imaging and spatial compounding has improved image quality significantly. ${ }^{12}$ THI showed superior image quality in the form of longer length of CBD, visualization, clarity of CBD lumen by reducing artifacts within the CBD, sharper outline of bile duct wall, clearer intraluminal filling defect.13

On ultrasonography stent appear as two echogenic parallel lines within the lumen. ${ }^{[14]}$ On ultrasound air appears as linear, bright echoes located adjacent to portal vein. Air in biliary system generally a result of communication with gastrointestinal tract by spincterotomy, passage of stone, endobiliary stent procedure, biliary enteric fistula or infection emphysematous cholecystitis or from reflux. ${ }^{12}$

Mechanical irritation due to contact of surface or tip of the stent with the biliary tract mucosal surface resulting in hyperemia, oedema and duct wall thickening (Cholengitis). Due to thickened bile duct wall in cholengitis due to stent may misdiagnosed as ductal dilatation. Ghazle et al had followed the patients of biliary dilatation after ERCP. Diffuse wall thickening was observed on follow up scan. Stent induced cholengitis should be considered when thickened, hypoechoic bile duct wall found on ultrasound. ${ }^{14}$ The presence of positive Murphy's sign and presence of gallstone are the most predictive of acute cholecytitis. Secondary signs of acute cholecystitis are gallbladder wall thickening of $>3 \mathrm{~mm}$, distended or hydropic gallbladder and pericholecystic fluid collection. ${ }^{[12]}$ Pancreatic visualization is possible in $75-93 \%$ cases irrespective of patient body weight and intestinal distension due to gas or food material.

A diameter exceeding $24 \mathrm{~mm}$ at the level of pancreatic body with marked anterior convexity of the pancreas with significant decrease in pancreatic echogenicity is seen in cases of acute pancreatitis. Stent induced cholangitis could be mistaken for biliary obstruction and dilatation. Complications of biliary stents includes early complications such as biliary infection (35\%), 
pancreatitis (29\%), bleeding (23\%), perforation (6\%), early stent migration(3\%), renal failure (3\%) and late complications as stent dysfunction (stent migration, stent occlusion), cholecystitis, duodenal perforation and bleeding ulcer. ${ }^{15}$

CONCLUSION: Ultrasound is a good diagnostic test in the assessment of biliary stent. As ultrasound is an easily available, cheap, noninvasive, non-radiational, cost-effective imaging modality, we recommend its use in the assessment of the status of biliary stent in follow up patients. Ultrasound additionally help in early detection of biliary dilatation in patients with biliary stent and confirm the absence of biliary dilation, detection of ERCP or stent complications, presence of cholangitis misinterpreted as biliary dilatation, stone and tumor status. Thus ultrasound will definitely help the clinician to confirm the presence of stent and additional pancratico-biliary information to guide the treatment.

\section{REFERENCES:}

1. Soehendra N, Reynders-Frederix V. Palliative bile duct drainage - a new endoscopic method of introducing a transpapillary drain. Endoscopy 1980; 12: 8-11.

2. Ballinger AB, McHugh M, Catnach SM, Alstead EM, Clark ML. Symptom relief and quality of life after stenting for malignant bile duct obstruction. Gut 1994; 35: 467-70.

3. Michael Pavlides and David A Gorard. Stents in Gastrointestinal Endoscopy Therapeutic Gastrointestinal Endoscopy www.intechopen.com.

4. Tarniţă D, Tarniță DN, Bîzdoacă N, Mîndrilă I, Vasilescu M. Properties and medical applications of shape memory alloys. Rom J Morphol Embryol 2009; 50: 15-21.

5. Bethge N, Sommer A, Gross U, Von Kleist D, Vakil N. Human tissue responses to metal stents implanted in vivo for the palliation of malignant stenoses. Gastrointest Endosc 1996; 43: 596602.

6. Shepherd HA, Royle G, Ross AP, Diba A, Arthur M, Colin-Jones D. Endoscopic biliary endoprosthesis in the palliation of malignant obstruction of the distal common bile duct: a randomized trial. Br J Surg 1988; 75: 1166-8.

7. Andersen JR, Sørensen SM, Kruse A, Rokkjaer M, Matzen P. Randomised trial of endoscopic endoprosthesis versus operative bypass in malignant obstructive jaundice. Gut 1989; 30: 1132-5.

8. Smith AC, Dowsett JF, Russell RC, Hatfield AR, Cotton PB. Randomised trial of endoscopic stenting versus surgical bypass in malignant low bile duct obstruction. Lancet 1994; 344: 1655-60.

9. Moss AC, Morris E, Leyden J, MacMathuna P. Malignant distal biliary obstruction: a systematic review and meta-analysis of endoscopic and surgical bypass results. Cancer Treat Rev 2007;33:213-21

10. O'Connor OJ, O'Neill S, Maher MM. Imaging of Biliary Tract Disease AJR 2011; 197:W551-8.

11. Rogoveanu I, Gheonea DL, Saftoiu A, Ciurea T. The Role of Imaging Methods in Identifying the Causes of Extrahepatic Cholestasis. J Gastrointestin Liver Dis 2006; 15: 265-71.

12. Rubens DJ. Ultrasound imaging of the biliary tract. Ultrasound Clin 2007; 2: 391-413.

13. Ortega D, Burns PN, Hope Simpson D, Wilson SR. Tissue Harmonic Imaging: Is It a Benefit for Bile Duct Sonography? AJR 2001; 176: 653-9. 


\section{ORIGINAL ARTICLE}

14. Ghazle H, Abu-Yousef M. Stent-Induced Cholangitis Mimicking Biliary Dilatation on Sonography Journal of Diagnostic Medical Sonography 2010; 26: 178.

15. Dumonceau JM, Tringali A, Blero D, Devière J, Laugiers R, Heresbach D, Costamagna G. ESGE Clinical Guideline for biliary stenting. Endoscopy 2012; 44: 277-298.

\section{AUTHORS:}

1. Prashant U. Titare

2. Bhawana D. Sonawane

3. Narendra G. Tembhekar

4. Pradip B. Rathod

5. Amitkumar W. Kamble

6. Aarti Anand

7. Suhasini N. Patil

8. Abhishek Mashirkar

\section{PARTICULARS OF CONTRIBUTORS:}

1. Assistant Professor, Department of Radiology, Government Medical College and Super-speciality Hospital, Nagpur, Maharashtra, India.

2. Professor, Department of Radiology, Government Medical College and Superspeciality Hospital, Nagpur, Maharashtra, India.

3. Associate Professor, Department of Radiology, Government Medical College and Super-speciality Hospital, Nagpur, Maharashtra, India.

4. Assistant Professor, Department of Radiology, Government Medical College and Super-speciality Hospital, Nagpur, Maharashtra, India.

\section{FINANCIAL OR OTHER} COMPETING INTERESTS: None
5. Assistant Professor, Department of Radiology, Government Medical College and Super-speciality Hospital, Nagpur, Maharashtra, India.

6. Associate Professor, Department of Radiology, Government Medical College and Super-speciality Hospital, Nagpur, Maharashtra, India.

7. House Officer, Department of Radiology, Government Medical College and Superspeciality Hospital, Nagpur, Maharashtra, India.

8. House Officer, Department of Radiology, Government Medical College and Superspeciality Hospital, Nagpur, Maharashtra, India.

\section{NAME ADDRESS EMAIL ID OF THE CORRESPONDING AUTHOR:}

Dr. Prashant Uddaorao Titare, C/o. M. G. Dahat, Plot No. 60, New Indira Colony, Bhagwannagar, Nagpur-440027, Maharashtra, India. E-mail: putitare@gmail.com

Date of Submission: 26/08/2015.

Date of Peer Review: 27/08/2015.

Date of Acceptance: 19/09/2015.

Date of Publishing: 28/09/2015. 